\title{
Effect of deoxycholate capped silver nanoparticles in seed dormancy breaking of Withania somnifera
}

\author{
Raja Muthuramalingam Thangavelu*, Bupesh Munisamy and \\ Kathiravan Krishnan \\ Nanobiotechnology Research Laboratory, Department of Biotechnology, University of Madras, Chennai 600 025, India
}

Plant population growth and persistence are strongly influenced by germination and recruitment, which can be dramatically affected by seed dormancy. Generally, pre-sowing weakens physical dormancy and initiates seed germination, but Withania somnifera seeds are an exception in this case. The basic objective of this study was to develop an alternate protocol to break the physical dormancy in $W$. somnifera seeds using deoxycholic acid capped silver nanoparticles (AgNPs). For this, high surface reactive silver nanoparticles were synthesized using sodium deoxycholic acid (NaDC) as a reducing agent $(\mathrm{NaDC}-\mathrm{AgNPs})$. Seed sets were concurrently soaked with NaDC-AgNPs (20 ppm), and sodium deoxycholate $(20 \mathrm{ppm})$, gibberellic acid $\left(\mathrm{GA}_{3}\right.$; $20 \mathrm{ppm}$ ) and water as control for different durations $(20,30,60$ and 90 min). Germination was initiated under tissue culture conditions. NaDC-AgNPs-treated seeds showed uniform germination quality of the highest order and increased total germination percentage (TGP) in short time; it was about $93.3 \%$ on the fifth day of culture. $\mathrm{GA}_{3}$ and NaDC-treated seeds showed TGP of 36.6 and 63.33 at the 15 th day of culture respectively. NaDC-AgNPs-treated seedlings showed enhanced growth by fresh weight $(31.33 \mathrm{mg})$, radicle length $(16.88 \mathrm{~mm})$ and cotyledon length $(8.21 \mathrm{~mm})$ compared to control. SEM analysis of seeds showed clear evidence of scarification effects over NaDC-AgNPs-treated seeds. Thus NaDC-AgNPs initiated early germination response in Withania seeds by breaking the physical dormancy with the highest TGP.

Keywords: Germination enhancer, nano-agriculture, sodium deoxycholate, seed dormancy breaking, silver nanoparticles.

TRADITIONALLY, herbs play an important role in healing; sometimes they are considered as a special category of plants, i.e. those particularly valued for their medicinal, savory or aromatic qualities ${ }^{1}$. Withania somnifera (L.) Dunal (family Solanceae) plant is an important herb in

\footnotetext{
*For correspondence. (e-mail: rajaronaldo8@gmail.com)
}

Ayurveda, the traditional Indian system of medicine. It stimulates the immune system and improves the memory. It also has some potential effects like anti-tumour, antiinflammation and anti-stress. Some indigenous people of South Africa use this plant for the treatment of sexually transmitted infections, asthma and also as an anti-inflammatory agent ${ }^{2,3}$. Traditionally, $W$. somnifera is propagated through seeds, but the mature and healthy seeds are not always available for germination. The viability period of the seeds is very short and their germination is also poor $^{4,5}$. The percentage of germination also is low due to the presence of certain inhibitory compounds in the fruit ${ }^{6}$. The reported maximum germination rate was low at $48 \%{ }^{7}$. To meet the growing demand from the pharmaceutical industry and traditional medicine, it is necessary to multiply this species by adopting in vitro techniques. Through seed dormancy, progression of the embryo into a seedling or plantlet is arrested. This process plays a vital role in the plant life cycle by allowing progeny to survive in adverse environmental conditions and to coordinate their growth with the most favourable conditions. In domesticated crops, this is barely necessary and has been eliminated by breeding ${ }^{8}$. The seed coat is a major determinant of dormancy, particularly in species with seed coat-imposed dormancy in which the embryo is physically constrained from developing further. This differs from embryo dormancy, where the embryos of certain species are dormant. Due to critical interplay between seed coat and embryo in some species ${ }^{9}$, the seeds will not germinate irrespective of the treatments; this phenomenon is known as complete or innate dormancy ${ }^{10}$. In some other species, biochemical block is incomplete and seeds will germinate over a narrow range of environmental conditions, this pattern is called conditional or relative dormancy ${ }^{8}$.

Two major causes for unsuccessful seed germination are hard seed coat (physical) and dormant seed embryo (embryonic). Physical dormancy is due to the presence of 3-5 layers of thick-walled endosperm cells and thick testa, which prevent the entry of water into the embryo; this is also called primary dormancy ${ }^{11}$. Physical dormancy was observed in freshly collected seeds of Solanaceae species, 
including $W$. somnifera. The physical dormancy is normally overcome by weakening the seed coat using chemical treatment, temperature shock, seed scarification and stratification $^{12-15}$. Several protocols (duration and compounds) were standardized to break the hard seed coat dormancy $^{15}$. However, these first generation dormancy breaking techniques were critical for key success due to damage of seeds or failure to break dormancy. These were the results of excessive or insufficient treatment respectively. Finding a superior way to break seed dormancy and simultaneously increasing the germination capability have been enforced in sustainable agriculture.

Currently, the discipline of nanoscience is growing rapidly with widespread applications in several fields. The use of nanoparticles (NPs) in the field of agriculture is gaining attention, especially in the controlled release of agrochemicals, efficient nutrient utilization and enhanced plant growth ${ }^{16}$. Significantly, researchers have already studied the effects of nanomaterials on plant germination and growth but not dormancy breaking ${ }^{17-19}$. Silver nanoparticles (AgNPs) due to their unique properties such as high specific surface area, catalytic efficiency, surface energy, abundant reactive sites and strong adsorption, may have significant effects on many organisms, especially plants which are an essential base component of all ecosystems ${ }^{20}$. The catalytic activity has been proved by the increased degradation of starch and amylase enzyme activity in the presence of the former ${ }^{21}$. AgNPs also exhibit proven photocatalytic activities ${ }^{22}$.

Sodium deoxycholate $(\mathrm{NaDC})$ is one of the two major bile salts produced by the mammalian liver, where it is synthesized from cholesterol. The characteristic feature of mammalian bile acid deoxycholate is a potential emulsifier, which is also traditionally practiced for seed germination by the source of cow dung ${ }^{23}$. However, it is assumed that the presence of bile salts in cow dung helps to break the seed coat and makes permeable to water and

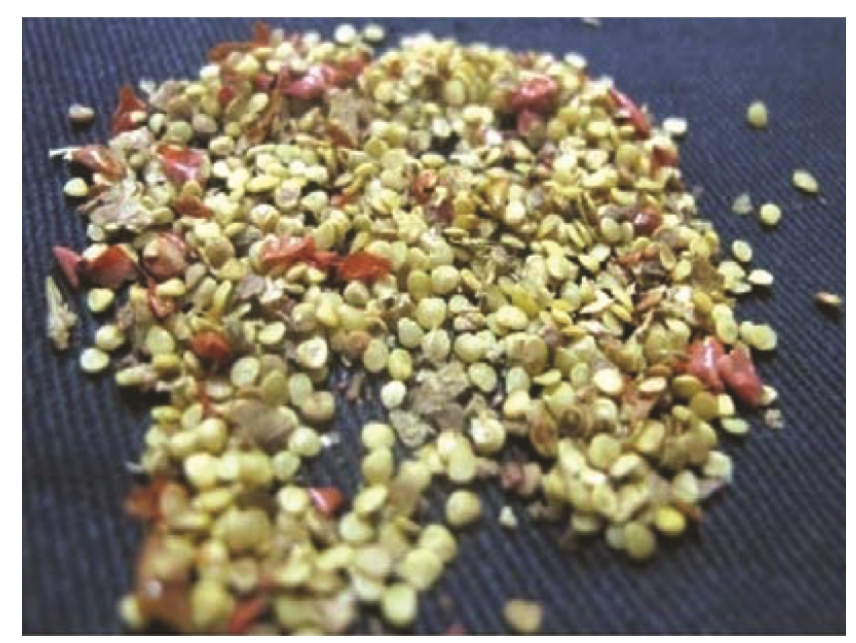

Figure 1. Withania somnifera shadow-dried seeds obtained from fruits. gas which is necessary for germination. Sodium deoxycholate, the sodium salt of deoxy cholic acid, is often used as a biological detergent in lysis cells, and to solubilize cellular and membrane compounds. Here, we develop a new methodology to treat Withania seeds using sodium deoxycholate-synthesized silver nanoparticles in order to break physical dormancy and enhance seed germination.

\section{Materials and methods}

\section{Chemicals}

Silver nitrate $(99.99 \%)$ and sodium deoxycholate (MW 414.55) were purchased from Sigma-Aldrich. Hormone gibberellic acid $\left(\mathrm{GA}_{3}\right)$, sodium hypochlorite $(\mathrm{NaOCl})$ and filter papers were obtained from Himedia Laboratories. Other fine chemicals and reagents used in the experiment were obtained from Sisco Laboratories. Glassware were purchased from Borosil. All glassware were thoroughly cleaned with aqua regia $\left(\mathrm{HCl}: \mathrm{HNO}_{3}=3: 1\right)$, rinsed with ultrapure water (Milli-Q), and dried in a hot-air oven prior to use.

\section{Synthesis of nanoparticles}

Sodium deoxycholate salt was used to prepare the required molar concentration of solution at $\mathrm{pH} 6.0$ in double-distilled water. The colloidal silver nanoparticles used were sodium cholate-stabilized silver nanoparticles (NaDC-AgNPs), prepared by the reduction of silver salt (silver nitrate) with sodium deoxycholate as reported earlier ${ }^{24}$. The obtained NaDC-AgNPs colloidal solution was characterized by UV-visible spectrophotometer (UV1601 spectrophotometer, Shimadzu, Japan) and highresolution transmission electron microscopy (HRTEM, FEI TECHNAI, G2 MODEL T-30 S-TWIN) for confirmation.

\section{Seed materials and culture plates}

Withania seeds used in the experiment were harvested from their natural populations in and around Palani hills $\left(10^{\circ} 12^{\prime} \mathrm{N} 77^{\circ} 28^{\prime} \mathrm{E}\right)$, Tamil Nadu, South India. The seeds were removed from the berries, air-dried and stored in paper bags in the temperature range $15-25^{\circ} \mathrm{C}$ (Figure 1). Various trials were conducted three weeks after collection. Only mature seeds were used in the experiments. The seeds were pale brown in colour and kidney-shaped. They were washed under running tap water for $30 \mathrm{~min}$ continuously and then a few drops of TWEEN-20 (polyoxy-ethylene-sorbitan monolaurate) were added. Subsequently, the seeds were surface-sterilized with $2.0 \% \mathrm{NaOCl}$ solution for $10 \mathrm{~min}$ to prevent microbial 

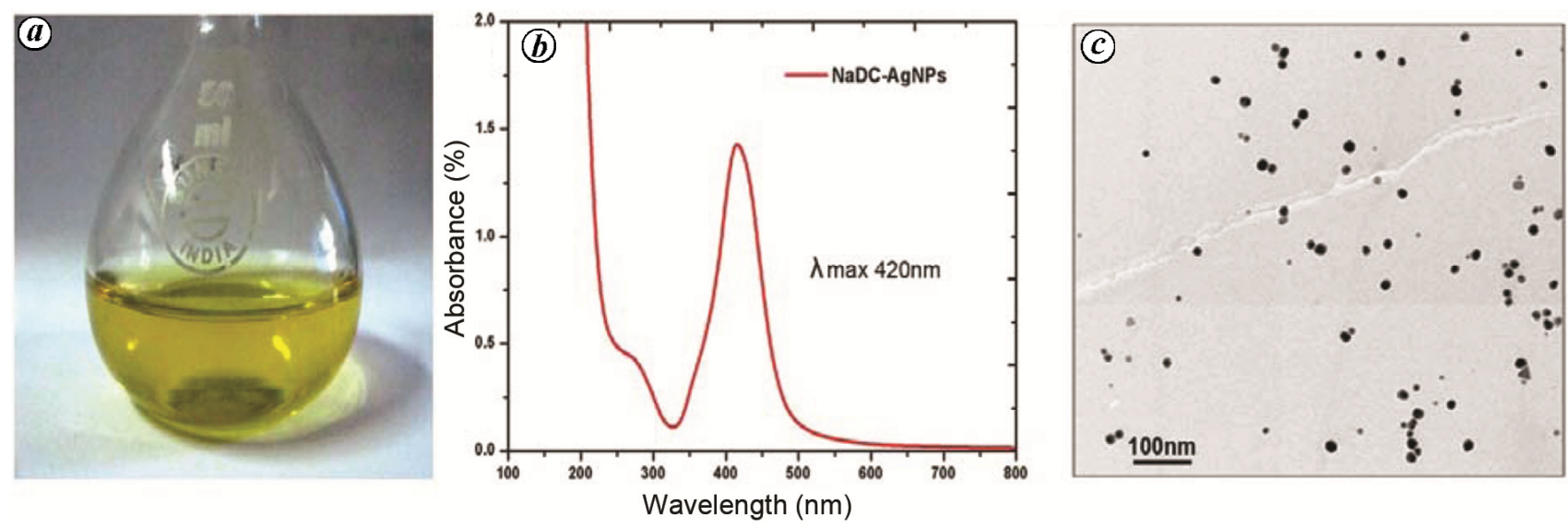

Figure 2. $\boldsymbol{a}$, Synthesized sodium deoxycholic acid (NaDC) capped silver nanoparticles in colloidal solution. $\boldsymbol{b}$, UV-Vis absorption spectra for $\mathrm{NaDC}-$ silver nanoparticles (AgNPs) showing $\lambda_{\max }$ at $420 \mathrm{~nm}$. $\boldsymbol{c}$, Transmission electron photomicrograph of NaDC $-\mathrm{AgNPs}(\mathrm{scale}$ bar $=100 \mathrm{~nm})$.
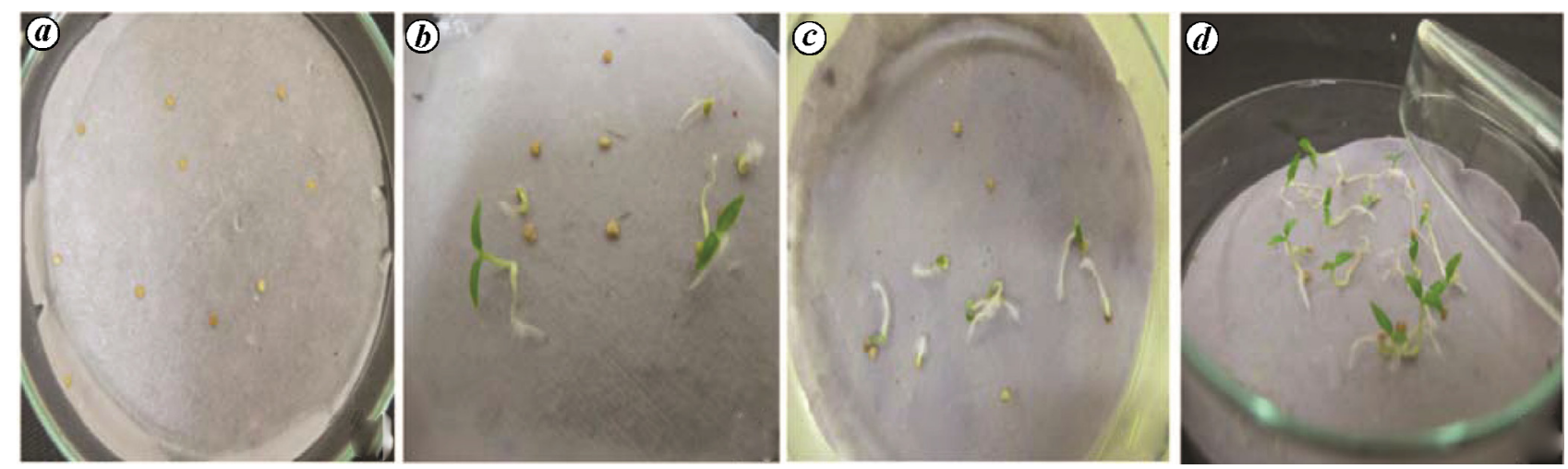

Figure 3. Petri dishes showing germination status of seeds treated with $(\boldsymbol{a})$ water, $(\boldsymbol{b})$ gibberellic acid $\left(\mathrm{GA}_{3}\right),(\boldsymbol{c}) \mathrm{NaDC}$ and $(\boldsymbol{d}) \mathrm{NaDC}-\mathrm{AgNPs}$.

contamination. The sterilized seeds were stored in sterilized vials until further studies. Seed viability test was also performed to ensure that the seeds used for the experiment were viable and of high quality; the sample group was subjected to viability using tetrazolium technique $^{25}$. Petri plates were initially washed with a detergent solution and then soaked in aqua regia for $30 \mathrm{~min}$ and rinsed with distilled water thrice. The plates were airdried and wiped with $70 \%$ ethanol and kept in a hot-air oven for $30 \mathrm{~min}$ for dry heat sterilization. Filter paper discs were placed inside the petri plates which were then autoclaved at $121^{\circ} \mathrm{C}$ for $15 \mathrm{~min}$.

\section{In vitro germination study}

In vitro germination trials were conducted in $9 \mathrm{~cm}$ diameter sterile petri dishes lined with filter paper and moistened with sterile distilled water to ensure adequate moisture for the seeds. Seed treatments included $1 \mathrm{ml}$ solution of $\mathrm{NaDC}(20 \mathrm{ppm}), \mathrm{GA}_{3}(20 \mathrm{ppm}), \mathrm{NaDC}-\mathrm{AgNPs}(\sim 20 \mathrm{ppm})$ and double-distilled water $\left(\mathrm{ddH}_{2} \mathrm{O}\right)$ at different time durations $(20,30,60$ and $90 \mathrm{~min})$. Treatments were performed inside the laminar air hood chamber under light irradiation. All the treatments were conducted in a completely randomized design. Immediately after treatment the seeds were carefully placed in petri dishes using sterile pipette tips. Then the plates were sealed with microfilm and kept under $16 \mathrm{~h}$ light and $8 \mathrm{~h}$ dark condition provided by cool white fluorescent lamps at $25^{\circ} \pm 2{ }^{\circ} \mathrm{C}$. Each treatment includes three replications (10 seeds each) and the experiment was repeated twice. The moisture level of the filter paper was maintained by adding sterile $\mathrm{ddH}_{2} \mathrm{O}$ as required. Seeds were examined daily and considered as germinated when the radicle was visible. The first germination was observed on the fifth day and final germination on the 15th day. At the end of the trials, growth parameters such as germination percentage, speed of germination, seedling fresh weight, radicle length and cotyledon length were subjected to analysis by mean separation and Duncan's multiple range test (DMRT) at $P=0.05$ using the SPSS software (SPSS, v. 11, Chicago, IL, USA). Graphs were plotted using OriginPro8 (originlab.com).

\section{Scanning electron microscopic analysis}

The seeds treated with four different solutions were subjected to surface morphology analysis using scanning 
electron microscopy (SEM). All seed samples were fixed in mixture of fixing solution (formaldehyde (40\%)-acetic acid-ethanol $(70 \%), 90: 5: 5)$, then dehydrated with an increasing series of acetone, and dried up to a critical point (Denton vacuum DCP-1 critical point drying apparatus). Later they were covered with gold-palladium by sputtering (Dentum vacuum desk II) and finally observed under SEM (JEOL 5800 LV).

\section{Acclimatization of AgNPs-treated plants}

Acclimatization is the significant process where in vitro cultured plants maintain their adaptation to the outer environment. The laboratory-grown plants of $W$. somnifera were acclimatized in the soil for survival or field test. Seedlings with $2 \mathrm{~cm}$ primary root and two cotyledon leaves were carefully taken out from the petri plates and transplanted in sterilized soil and sand mixture $(3: 1)$. Small holes were made in each plastic bag to maintain high humidity and the bags were kept in culture room for acclimatization. After about 30 days, the plants were transferred to bigger pots in the greenhouse and maintained under natural conditions of day length, temperature and humidity. Finally, the plants were transferred to field conditions.

\section{Results and discussion}

\section{$N a D C-A g N P s$}

The synthesized NaDC-AgNPs colloidal solution was yellow in colour, corresponding to silver nanoparticles and their surface plasmonic resonance (Figure $2 a$ ). The UVVis absorbance spectra (Figure $2 b$ ) of the synthesized NaDC-AgNPs also confirmed particle synthesis in the solution that gave maximum absorbance spectra at $420 \mathrm{~nm}$, which is universal for silver nanoparticles. The synthesized particles were observed to be nearly spherical in shape with average size of $22 \mathrm{~nm}$ in diameter in electron microscopy image (Figure $2 c$ ). This wet chemistry synthesis method yielded NaDC-AgNPs concentration of $\sim 0.02 \mathrm{mg}(20 \mathrm{ppm})$ in $1 \mathrm{ml}$ solution. The synthesized nanoparticles were stable for 7-9 months under room temperature and when stored in a dark place.

\section{Seed germination study}

Seed germination was observed by the emergence of primary root (radicle) from the micropyle region of the seed. Experimental results showed that treatment of seeds with NaDC-AgNPs had significantly better effect than treatments with $\mathrm{NaDC}, \mathrm{GA}_{3}$ and water (Figures 3-5). Different time incubation periods $(20,30,60$ and $90 \mathrm{~min})$ with test solutions showed good impact on germination rate. Seeds treated with water induced no germination and the rate of germination was zero till the last day (15th) of culture (Figures $3 a, 4$ and 5). The seeds treated with $\mathrm{GA}_{3}$ induced little response in germination at the 60 and $90 \mathrm{~min}$ treatment time. Poor germination percentage (23.3-36.6) was achieved by $\mathrm{GA}_{3}$ on the 13th day of culture in petri dishes (Figures $3 b, 4$ and 5). NaDC-treated seeds showed gradual improvement in the rate of germination (0-63.3\%) at increased treatment time (Figures $3 c, 4$ and 5). The mean germination days also reduced from 15 to 8 at $90 \mathrm{~min}$ treatment. Moreover, significantly and surprisingly, seeds soaked with $\mathrm{NaDC}-$ AgNPs recorded higher TGP (93.3) in 90 min treatment on the fifth day of culture in petri dishes (Figures $3 d, 4$

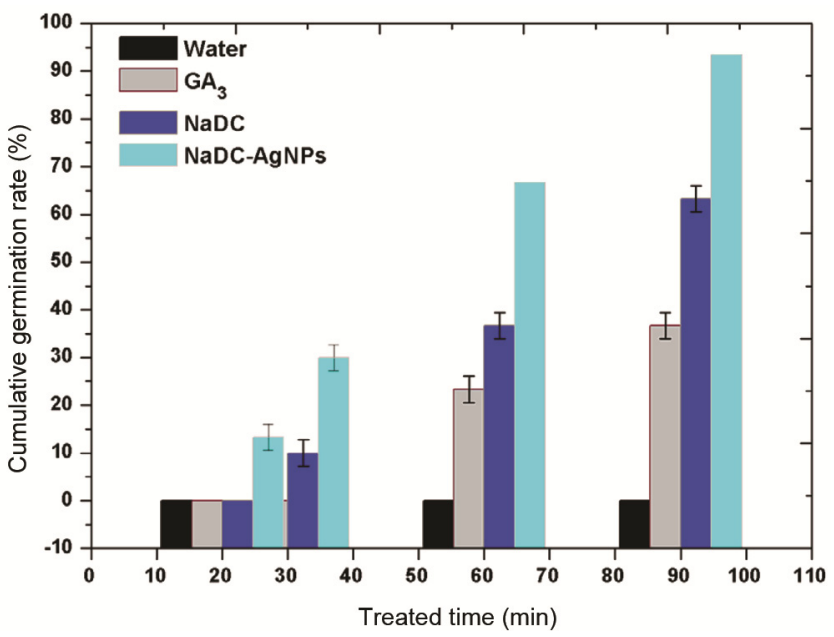

Figure 4. Bar graph showing cumulative germination rate (\%) of treated seeds versus treatment time with water, $\mathrm{GA}_{3}, \mathrm{NaDC}$ and $\mathrm{NaDC}-$ AgNPs. The data represent mean $\pm \mathrm{SD}$ values and the bar diagram represents a percentage of total germination with standard error values.

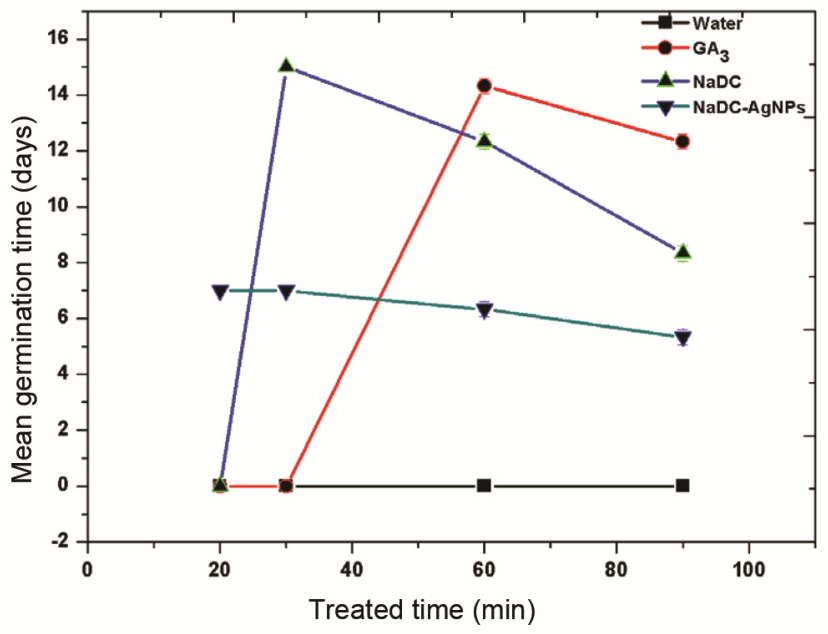

Figure 5. Graph showing mean germination time (days) of treated seeds versus treatment time with water, $\mathrm{GA}_{3}, \mathrm{NaDC}$ and $\mathrm{NaDC}-$ AgNPs. The data represent mean $\pm \mathrm{SD}$ values and the bar diagram represents germination days with standard error values. 
Table 1. Effect of water (control), gibberellic acid $\left(\mathrm{GA}_{3}\right)$, sodium deoxycholic acid $(\mathrm{NaDC}), \mathrm{NaDC}-$ silver nanoparticles (AgNPs) treatments on Withania seedling growth after 15 days of sowing

\begin{tabular}{lccc}
\hline Treated in solution & $\begin{array}{c}\text { Seedling fresh } \\
\text { weight }(\mathrm{mg})\end{array}$ & $\begin{array}{c}\text { Radicle length } \\
(\mathrm{mm})\end{array}$ & $\begin{array}{c}\text { Cotyledon } \\
\text { length }(\mathrm{mm})\end{array}$ \\
\hline Water & $0^{*}$ & $0^{*}$ & $0^{*}$ \\
$\mathrm{GA}_{3}$ & $22.61^{\mathrm{b}}$ & $13.2^{\mathrm{b}}$ & $5.89^{\mathrm{b}}$ \\
$\mathrm{NaDC}$ & $23.43^{\mathrm{b}}$ & $13.77^{\mathrm{b}}$ & $6.04^{\mathrm{b}}$ \\
$\mathrm{NaDC}-$ AgNPs & $31.33^{\mathrm{a}}$ & $16.88^{\mathrm{a}}$ & $8.21^{\mathrm{a}}$ \\
\hline
\end{tabular}

*0, No response. Data collected from three separate experiments each containing 10 seeds per petri plate. Mean values within the column with the same superscript are not significantly different $(P<0.05$; Duncan's New Multiple Range Test).
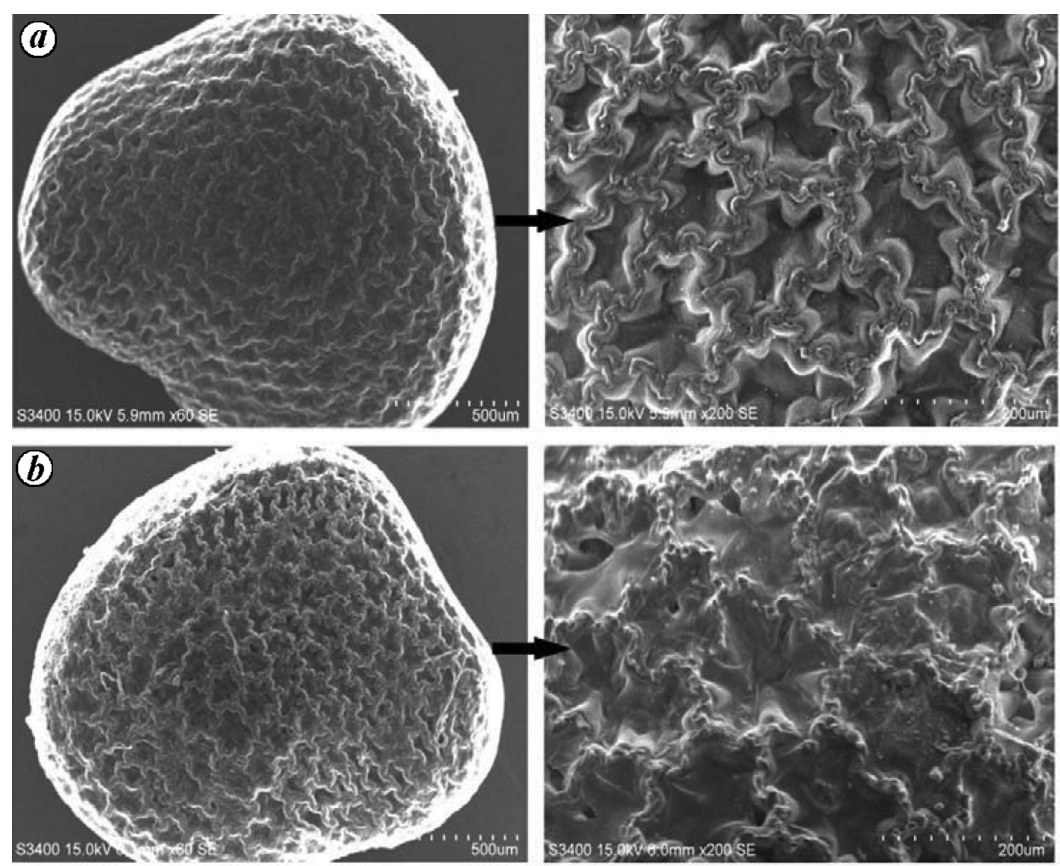

Figure 6. Scanning electron microscopic images of Withania seeds: (a) Control treated and (b) NaDCAgNPs treated.

and 5). Similarly, lower soaking time (20, 30 and $60 \mathrm{~min})$ also resulted in optimum germination percentage (14-66), which was higher than the other treatments. Compared with $\mathrm{NaDC}$ treatment, $\mathrm{NaDC}-\mathrm{AgNP}$ resulted in twofold enhanced germination and growth of seedlings. Thus, 90 min duration is found to be effective for enhancing early germination and increased rate of germination for both $\mathrm{NaDC}$ and $\mathrm{NaDC}-\mathrm{AgNPs}$.

The $\mathrm{GA}_{3}$-treated seedlings that emerged after the 15 th day showed optimum growth such as seedling fresh weight $(22.61 \mathrm{mg})$, radicle length $(13.2 \mathrm{~mm})$ and cotyledon length $(5.89 \mathrm{~mm})$. NaDC-treated seedlings after the 15 th day showed enhanced growth, which was more than $\mathrm{GA}_{3}$-treated seedlings $-23.43 \mathrm{mg}$ of fresh seedling weight, $13.77 \mathrm{~mm}$ radicle length and $6.06 \mathrm{~mm}$ cotyledon length. NaDC-capped AgNPs-treated seeds showed effective response to growth of seedlings - fresh weight $(31.33 \mathrm{mg})$, radicle length $(16.88 \mathrm{~mm})$ and cotyledon length $(8.21 \mathrm{~mm})$. Then the results indicate that seed dormancy exhibited $W$. somnifera is entirely due to phys- ical dormancy, where treatment with NaDC-capped AgNPs at 90 min is sufficient to overcome the dormancy in an effective way.

\section{SEM analysis of treated seeds}

With respect to different seed treatments, only NaDCcapped AgNPs were found to alter the surface texture of seed coat (testa). Figure $6 a$ and $b$ shows the controltreated and NaDC-capped AgNPs-treated seed surface morphology respectively. The seed coat is normally hard and water-resistant. However, seeds treated with NaDCAgNPs had ruptured seed coat, which is similar to the physical method called scarification. The micropyle region in the seed coat was also found ruptured in SEM analysis. Thus, water can reach the embryo and initiate germination. Seeds of other treatments showed no evidence of seed coat alteration. Possibly NaDC alone serves as an effective agent in dormancy breaking without seed coat alteration. 

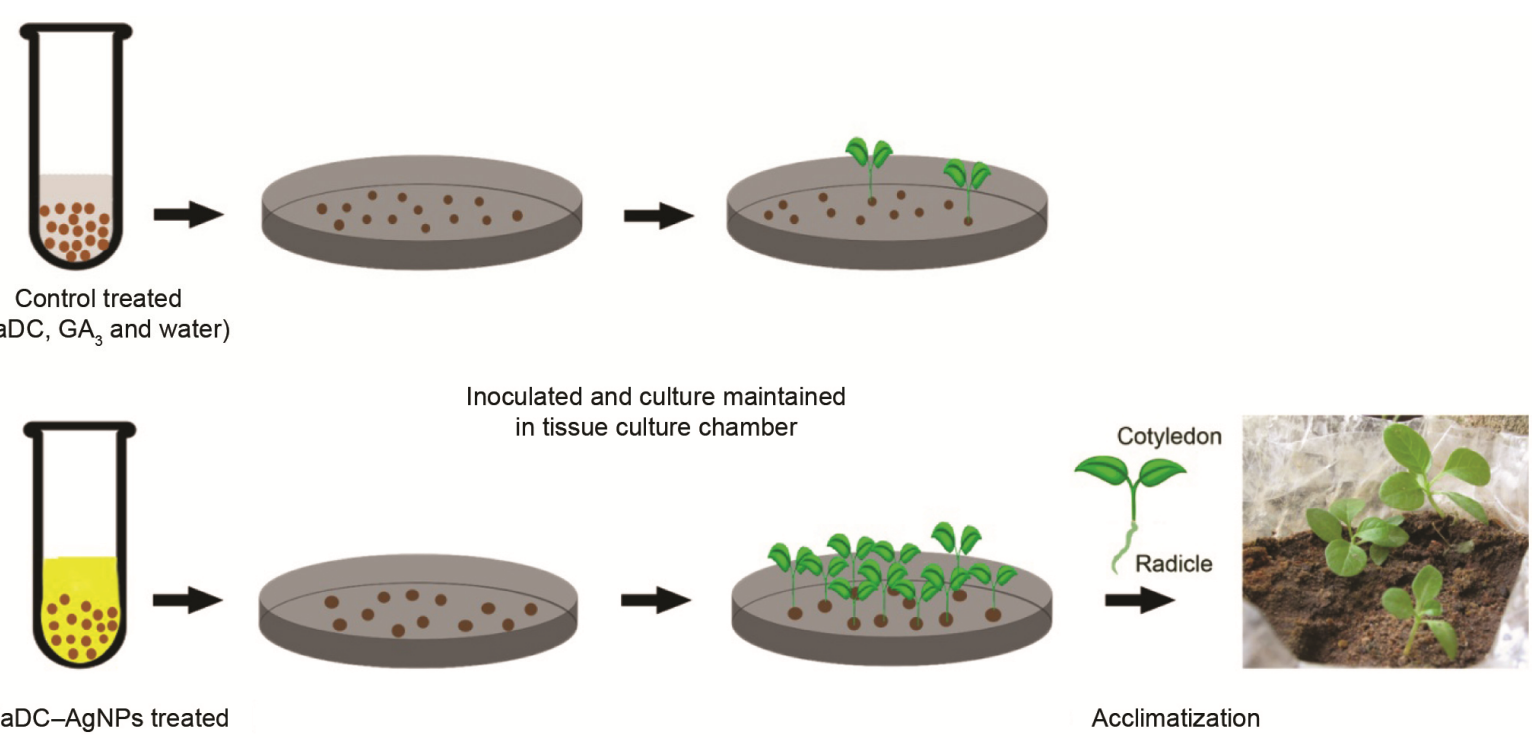

Figure 7. Scheme of nanoparticles-assisted seed dormancy breaking and enhanced germination.

\section{Discussion}

An earlier study found that $\mathrm{GA}_{3}$ promoted growth and proved successful in breaking the dormancy ${ }^{26}$. It functions by promoting induction of cell hydrolase and endosperm weakening which is the main cause of dormancy in the Solanaceous family and W. somnifera ${ }^{12}$. Seed dormancy of ashwagandha has been overcome by treating the seeds with $\mathrm{KNO}_{3}(1 \%)$ for about $6 \mathrm{~h}$ followed by $\mathrm{GA}_{3}$ treatment that recorded a germination rate of $78 \%$ (ref. 15). No earlier study has reported germination rate above $80 \%$. Only NaDC-capped AgNPs were able to attain 93\% success rate in dormancy breaking of Withania and ashwagandha seeds.

Sodium deoxycholate is often used as a biological detergent for lysis cells and to solubilize cellular and membrane compounds ${ }^{26}$. Hence, this surfactant is able to solubilize the seed coat, thus allowing water to penetrate inside the seed. Cholic acid is a primary bile acid present in animal faeces. Plants in fecal seeded plots reported having a greater growth $\operatorname{size}^{27}$. Nanoparticles by themselves do not confer specific binding to biological targets, which is a prerequisite for their use in a biological framework. This means that the particles have to be coupled to biomolecules that harbour such specificities. In the case of silver nanoparticles, it has some proven properties of binding specificity with biological systems. Silver nanoparticles due to their unique properties such as high specific surface area, catalytic efficiency, surface energy, abundant reactive sites and strong adsorption may have significant effects on many organisms ${ }^{21}$. Their catalytic activity has also proven in the degradation of starch along with the amylase enzyme. The findings of the present study are much correlated with previous studies. In this study, silver nanoparticles have shown synergistic effects on seeds, which resulted in the scarification of seed coat. The AgNPs along with sodium cholate surfactant ruptured the seed coat of Withania seeds and made it permeable for moisture to enter the micropylar region, thereby breaking its dormancy and successfully initiating early germination. SEM analysis confirmed that AgNPstreated seeds had ruptured testa and micropyle region. This led to early germination of Withania seeds in order to achieve higher germination rate with better seedling growth. Figure 7 illustrates the research scheme followed in this study.

\section{Conclusion}

Plant population have strongly influenced by their germination efficiency, which can be greatly affected by seed dormancy. In the case of $W$. somnifera, a highly valuable medicinal plant, due to seed dormancy it could not meet the demands of traditional medicine practice. Dormancy in Withania seeds can be overcome when the seed coat weakens or the embryo increases in growth potential, or a combination of both. Treatment of $W$. somnifera seeds with NaDC-capped AgNPs for 90 min resulted in germination percentage that was considerably higher than the control during the entire culture period; it effectively reached $93 \%$. Nitrates and gibberellins have been widely used to overcome seed dormancy, but they produced lower rate of germination ${ }^{28}$. Immersion of $W$. somnifera seeds in $\mathrm{GA}_{3}$ initiated germination after 15 days with germination percentage of $60 \%$ (ref. 29) whereas early germination was recorded with $\mathrm{NaDC}$-capped AgNPs treatment which initiated germination within 5 days. The capping agent of sodium deoxycholate alone also served as a good inducer for breaking dormancy in Withania seeds, which also scored higher germination percentage than $\mathrm{GA}_{3}$. It can be concluded that $\mathrm{NaDC}$ is a known strong surfactant that can easily solubilize compounds 


\section{RESEARCH ARTICLES}

present in the seed coat. Silver nanoparticles act as a powerful catalyst that can complex with biological entities such as seed coat which might be the result of seed invigoration. However, seed treated both $\mathrm{NaDC}$ and silver in combined form (NaDC-AgNPs), could be a better solution that addresses physical dormancy problems in other valuable seed materials. The dormancy of $W$. somnifera seeds is due to its hard seed coat. In acclimatization conditions, seedlings treated with NaDC capped AgNPs were observed healthy with enhanced growth. This approach of using silver nanoparticles for breaking seed dormancy can be easily followed in plant nursery.

1. Raja Muthuramalingam, T., Mohammed Riyaz, S. U., Dharanivasan, G., Jesse, M. I. and Krishanan, K., Effective ex situ conservation of endangered species Beloperone plumbaginifolia nees: a medicinal plant. Int. J. Plant, Anim. Environ. Sci., 2014, 4(2), 97102

2. BalKrishna, G., Bimal Kumar, G. and Kweon, H., Seed characteristics of Withania somnifera (Solanaceae). Korean J. Plant Taxon., 2011, 41(2), 103-107.

3. Marie Winters, N. D., Ancient medicine, modern use: W. somnife$r a$ and its potential role in integrative oncology. Altern. Med. Rev., 2006, 11(4), 269-272.

4. Vakeswaran, V. and Krishnasamy, V., Improvement in storability of Ashwagandha (Withania somnifera Dunal) seeds through prestorage treatments by triggering their physiological and biochemical properties. Seed Technol., 2003, 25, 203.

5. Siddique, N. A., Bari, M. A., Shahnewaz, S., Rahman, M. H., Hasan, M. R., Khan, M. S. I. and Islam, M. S., Plant regeneration of Withania somnifera (L.) Dunal (Ashwagandha) from nodal segments derived callus: an endangered medicinal plant in Bangladesh. Islam J. Biol. Sci., 2004, 4, 219-223.

6. De Silva, M. A. N. and Senarath, W. T. P. S. K., In vitro mass propagation and greenhouse establishment of Withania somnifera (L.) Dunal (Solanaceae) and comparison of growth and chemical compounds of tissue cultured and seed raised plants. J. Natl. Sci. Found. Sri Lanka, 2009, 37, 4.

7. Kambizi, L., Adebola, P. O. and Afolayan, A. J., Effects of temperature, pre-chilling and light on seed germination of Withania somnifera: a high value medicinal plant. S. Afr. J. Bot., 2006, 72, 11.

8. Bewley, J. D., The seed germination and dormancy. Plant Cell, 1997, 9, 1055-1066.

9. Jaimie, A. M., Shuyou, H., Loreta, G. S., Douglas, A. J. and Brian L. A. M., Seed coats: structure, development, composition and biotechnology. In vitro Cell. Develop. Biol.-Plant, 2005, 41, 620-644.

10. Burrows, C. J., Patterns of delayed germination in seeds. N. Z. Natl. Sci., 1995, 16, 13-17.

11. Debeaujon, I. O., Leon-Kloosterziel, K. M. and Koornneef, M. Influence of the Testa on seed dormancy, germination, and longevity in Arabidopsis. Plant Physiol., 2000, 122(2), 403-414.

12. Kattimani, K. N., Reddy, Y. N. and Rao, R. B., Effect of presoaking seed treatment on germination, seedling emergence, seedling vigour and root yield of Ashwagandha (Withania somnifera Daunal.). Seed Sci. Technol., 1999, 27, 483-488.

13. Zubaida, Y., Zabta Khan, S. and Ajab Khan, M., Phenetic analysis of medicinally important species of the Genus Solanum form Pakistan. Pak. J. Bot., 2010, 42(3), 1827-1833.

14. Gehen Jayasuriya, K. M. G., Jerry, M. B., Robert, L. G. and Carol, C. B., Seed development in Lpomea lacanosa (Convolulaceae), with particular reference to anatomy of the water gap. Ann. Bot., 2007, 100(3), 459-470.

15. Janglepanavar, R. F., Studies on seed dormancy and invigoration in ashwagandha. Karnataka J. Agric. Sci., 2010, 23(5), 816-874.

16. Raja Muthuramlingam, T., Dharanivasan, G., Michael Immanuel, J., Deepan, S., Mohammed Riyaz, S. U. and Kathiravan, K., Nanobiotechnological approach using plant rooting hormones synthesized silver nanoparticle as a 'nanobullets' for the dynamic applications in horticulture - an in vitro and ex vitro study. Arab. J. Chem., 2016, 11(1), 48.

17. Mondal, A., Basu, R., Das, S. and Nandy, P., Beneficial role of carbon nanotubes on mustard plant growth: an agricultural prospect. J. Nanoparticle Res., 2011, 13, 4519-4528.

18. Ei-Temsah, Y. S. and Joner, E. J., Impact of $\mathrm{Fe}$ and $\mathrm{Ag}$ nanoparticles on seed germination and differences in bioavailability during exposure in aqueous suspensions and soil. Environ. Toxicol., 2010, 27(1), 42-49.

19. Zheng, L., Hong, F., Lu, S. and Liu, C., Effect of nano- $\mathrm{TiO}_{2}$ on strength of naturally aged seeds and growth of spinach. Biol. Trace Elem. Res., 2005, 104, 83-91.

20. Juhel, G., Batisse, E., Hugues, Q., Daly, D., Van pelt, F. N., O Halloran J. and Jansen, M. A., Alumina nanoparticles enhance growth of Lemna minor. Aquat Toxicol., 2011, 105(3-4), 328-326.

21. Ernest, V., Shiney, P. J., Mukherjee, A. and Chandrasekaran, N., Silver nanoparticles: a potential nanocatalyst for the rapid degradation of starch hydrolysis by amylase. Carbohydr. Res., 2012, 352, 60-64.

22. Lee, B. T., Han, J. K., Gain, A. K., Lee, K. H. and Saito, F., TEM microstructure characterization of nano $\mathrm{TiO}_{2}$ coated on nano $\mathrm{ZrO}_{2}$ powders and their photocatalytic activity. Mater. Lett., 2006, 60, 2101-2104.

23. Jinichiro, K., Hidetoshi, K., Shuichi, G., Kenji, U., Masao, O. and Toshiaki, K., Cholic acid, a bile acid elicitor of hypersensitive cell death, pathogenesis-related protein synthesis, and phytoalexin accumulation in rice. Plant Physiol., 2006, 140, 1475-1483.

24. Raja Muthuramalingam, T., Chandrasekar, S., Dharanivasan, G., Nallusamy, D., Rajendran, N. and Kathiravan, K., Bioactive bile salt capped silver nanoparticles activity against destructive plant pathogenic fungi through in vitro system. RSC $A d v$., 2015, 5, 71174.

25. Grabe, D. F. (ed.), Tetrazolium Testing Hand-book for Agricultural Seeds/Prepared by the Tetrazolium Testing Committee of the Association of Official Seed Analysts, 1970; https://trove.nla.gov. au/version $/ 45195830$

26. Richard, E. B., Chemistry and the living organism, 4th edition (Bloomfield, Molly, M.). J. Chem. Educ., 1988, 65(8), 214.

27. Ocumpaugh, W. R., Archer, S. and Stuth, J. W., Switchgrass recruitment from broadcast seed vs seed fed to cattle. J. Range Manage., 1995, 49(4), 368-371.

28. Dewir, Y. H., Mahrouk, M. E. S. E. and Naidoo, Y., Effects of some mechanical and chemical treatment on seed germination of Sabal palmetto and Thrinax morrisii palms. Aust. J. Crop Sci., 2011, 5(3), 248-253.

29. Bharath, V. P. L., Standardization of seed testing procedures and storage studies in selected medicinal crops. M Sc. (Agric.) thesis, University of Agricultural Sciences, Dharwad, 2008.

ACKNOWLEDGEMENT. We thank the National Centre for Nanoscience and Nanotechnology, the University of Madras, Chennai for providing the characterization facilities.

Received 3 December 2018; accepted 18 December 2018

doi: $10.18520 / \mathrm{cs} / \mathrm{v} 116 / \mathrm{i6} / 952-958$ 